\title{
International students at the University of Cuenca: A study of their needs and perceptions ${ }^{1}$
}

\author{
Lourdes Montserrat Sánchez Rodas ${ }^{1}$, Hubert B. Van Hoof ${ }^{2}$, Alei (Aileen) Fan ${ }^{3}$, Narcisa Ullauri ${ }^{4}$ \\ ${ }^{1}$ MA, Escuela de Turismo, Universidad de Cuenca, Cuenca, Ecuador. \\ ${ }^{2}$ PhD, School of Hospitality Management, Penn State University, PA 16801, USA. \\ ${ }^{3} \mathrm{PhD}$ candidate, School of Hospitality Management, Penn State University, PA, USA. \\ ${ }^{4}$ MA, Escuela de Turismo, Universidad del Azuay, Cuenca, Ecuador. \\ Autor para correspondencia: lourdes.montserrat@ucuenca.edu.ec
}

Fecha de recepción: 1 de octubre de 2015 - Fecha de aceptación: 16 de noviembre de 2015

\begin{abstract}
This manuscript discusses a study that was conducted among incoming international exchange students at the University of Cuenca, Ecuador in the period 2011-2013. Its focus was not on the students' educational experiences, but rather on their opinions about the tourism services that were provided and on their travel preferences. Several comparative analyses of the opinions of males vs. females and of Latin American students vs. European/US students found significant differences of opinion regarding the various experiences. The manuscript makes a contribution to the literature in its focus on the students' perceptions about tourism services in Ecuador and on their travel behaviors. It offers practical recommendations for university administrators, tourism executives and policy makers as they try to enhance the country's tourism offerings and to improve Ecuador's image as a safe, welldeveloped tourism destination and as a welcoming site for international exchange students.
\end{abstract}

Keywords: Cuenca, Ecuador, higher education, incoming exchange students' opinions, international student exchange programs, tourism services.

\section{RESUMEN}

Este manuscrito describe un estudio que se llevó a cabo entre los estudiantes internacionales de intercambio que ingresaron en la Universidad de Cuenca, Ecuador. No se centró en las experiencias educativas de los estudiantes, sino más en sus opiniones sobre los servicios turísticos que estaban disponibles para ellos y sus preferencias de viaje. Varios análisis comparativos de las opiniones de los hombres frente a las mujeres y de los estudiantes de América Latina frente a los estudiantes europeos y estadounidenses encontraron diferencias de opinión significativas. El manuscrito hace una contribución teórica a través de su enfoque en las percepciones de los estudiantes acerca de los servicios turísticos en el Ecuador y en sus comportamientos de viaje. Ofrece recomendaciones prácticas para los administradores universitarios, ejecutivos de turismo y políticos responsables en sus esfuerzos para mejorar la oferta turística del país y mejorar la imagen de Ecuador como un destino turístico bien desarrollado y seguro y como un lugar acogedor para los estudiantes de intercambio internacional.

Palabras clave: Cuenca, Ecuador, educación superior, opiniones de los estudiantes de intercambio, programas de intercambio internacionales, servicios de turismo.

\footnotetext{
${ }^{1}$ This article was distilled and adjusted to the English language from a thesis submitted for the completion of the degree of Maestría en Planificación del Turismo II at the Universidad del Azuay by the lead autor, entitled "Análisis de la oferta y la demanda de turismo académico que visita la Universidad de Cuenca, período 20112013."
} 


\section{INTRODUCTION}

Students participating in international exchange programs learn in several ways: they learn from living in another culture, from being part of an academic program at a university other than their home institutions, from being taught by different professors and from their travel experiences while being abroad. It is difficult to separate the effects of each of these on the students' personal and academic growth or to determine what the true gains are to a student, yet consensus exists among the thousands of studies that have been done on the topic that personal growth and academic accomplishment occur because of the experience (Stone \& Petrick, 2013).

The University of Cuenca also offers its students the opportunity to study abroad at one of its international exchange partner institutions in Europe, the United States, or Latin America. In return, it is committed to receiving incoming students from those partner institutions. The university has limited control over the quality of the academic and personal experience of its own students abroad: it can work with its partners in designing the students' curricula, suggesting and even limiting what courses students can and cannot take. It can do so by finding equivalent courses at home, making housing and travel arrangements ahead of time and asking for administrative supervision and support of its students once they arrive abroad. Yet, the reality is that it will have to trust its partner institutions abroad to provide its students with a good experience. Any good partnership is built on trust; if the trust is no longer there, the partnership will have run its course and the partners should go their separate ways.

What the University of Cuenca can control, however, is how it treats and educates the students from its partner institutions who come to live and study in Cuenca for a semester. The better these students are treated in their studies, in their living arrangements and in the programs that are provided to them, the more valuable their academic experience will be. The more enriching their cultural immersion and the better the travel experiences of these students, the more the partner institutions abroad are inclined to send new students to Cuenca. This will not only lead to more opportunities for students from the University of Cuenca in those universities abroad; it might also convince additional universities in other countries to engage in exchange partnerships. For a growing country like Ecuador, with an academic system that is still developing and finding its place on the global academic radar, it is essential that incoming international students are treated as well as possible and that they surrounded with care and interest, both inside and outside the classroom. In its efforts to be as welcoming and accommodating as possible towards incoming students, the university needs information from those students: it needs to know what support they need academically, what their needs are with regard to housing, travel and accommodation, what their budgets are, what the level of their language skills is, where they travel, and how they feel about safety and health issues, just to name a few.

The study reported here was designed to look into some of those issues: it investigated the perceptions of incoming international students with regard to the services they used, bothin the city of Cuenca and while they were travelling. It collected information about the students' budgets, their language skills, and their travel experiences, and it provided sufficient information for the researchers to compare student opinions based on gender and origins. The former comparison was done to determine if the needs and perceptions of females were different from those of the male students; the latter provided information about the needs and perceptions of Latin American students as compared to the needs and perceptions of students from other parts of the world. After a review of the literature on the topic, this manuscript will describe the survey design and the data collection and provide a discussion of the descriptive results of the data analysis and of the outcomes of the comparative analyses between the various groups in the sample before offering concluding remarks and suggestions for future research. 


\section{REVIEW OF LITERATURE}

Over the past fifty years numerous articles have been published about the benefits of students living, working and studying abroad. In the earlier stages of those international exchange or "study abroad" programs, those studies primarily focused on the benefits of the international experience, both from an educator and from a student perspective. The most common benefit identified in earlier studies was the students' exposure to different social and cultural environments (Swanson, 1969; Arndt, 1984; Lamey, 1990; Calleja, 1995; Saliba, 1995). Studies found that living and being part of another culture changed student perceptions about other cultures and nationalities (Stangor et al., 1994). The experience was found to present them with an alternative view of the world (Remy et al., 1975) as students recognized that their own social and cultural values and norms were different from those of their counterparts in their host countries (Carlson \& Widaman, 1988; Drews et al., 1996; Roberts, 1998; Chieffo \& Griffiths, 2004; Sutton \& Rubin, 2004), an important development given the age and the maturity levels of the students. As university students, their personalities are still developing and they still search for their own identities. They are, at best, only "young adults."

With regard to students being "young adults," it was found that students who participated in exchange programs tended to be more mature than their peers who did not study abroad (Frish,1990; Fernández et al., 2013) and that an international study experience helped them in that maturation process. International study abroad programs help shape students into becoming rounded, culturally sensitive individuals, which has been one of the guiding principles of higher education around the world (Hadis, 2005). As Vestal (1994: 15) states: "These programs are commonly based on the conviction that quality education must reflect and encompass knowledge of diverse societies and cultures as well as the realities of global interdependence". So, as universities across the globe make considerable efforts to "internationalize" their programs and their curricula, international student exchange programs fit in very well with those efforts and prepare students better for the workplace of the future(Barnett \& Wu, 1995; Lawson et al., 1998; Mohareji \& Gillespie, 2003; Silberleib, 2005; Van Hoof, 2006; Carrera, 2010).

Whereas those early studies primarily focused on the most important educational advantages and on the developmental benefits of international education, more recent research has focused much more on concrete issues, such as the outcomes of such programs (Van Der Wende \& Westerheijden, 2010; Norris \& Gillespie, 2003; Paige et al., 2009; Daly \& Barker, 2010), barriers to international student mobility (Souto-Otero et al., 2013), factors that determine student participation (Doyle et al., 2010; Stone \& Petrick, 2013)), costs and benefits of those programs (Messer \& Wolter, 2001), various developmental strategies available (Altbach \& Teichler, 2001; Altbach \& Knight, 2007) and on how to evaluate their structure and effectiveness across national borders (Gacel Avila, 2007).

In Europe, along with the socio-political changes of late twentieth and early twenty-first century that lead to the creation of the European Union, the international student exchange experience was further institutionalized by means of the Bologna agreement (Pechar, 2007; Brunner, 2009; Palese et al., 2014), an attempt to unify higher education standards across national borders. The Bologna Process currently has 47 participating countries in Europe and encourages higher education systems in its member states to organize themselves in such a way that it is easy for students and faculty to move from one country to the other for the purpose of further study or employment. It also aims to create greater synergy between the U.S. and Europe as European higher education institutions have adopted certain aspects of the American system, such as bachelor and master degree programs and titles.

A second, fairly recent, development in Europe was the Erasmus program which was designed and implemented in 1987 in order to develop and grow student exchange programs among institutions of higher education on the continent in particular (Juvan \& Lesjak, 2011; Rodriquez-Gonzalez et al., 1987; Mutlu, 2011). The earlier Erasmus Program was later incorporated into the Socrates Program in 1994 and replaced with the Socrates II Program in 2000, which, in turn, was replaced by the Lifelong Learning Program in 2007. There are currently more than 4,000 institutions of higher education participating in this across the continent and in 2012-13 alone, 270,000 students took part in it. The program guarantees that the period that is spent abroad is recognized by a student's university when he/she comes back as long as they abide by the terms that were agreed upon and signed off on before 
departure. Students do not pay extra tuition fees to the university they visit abroad and they can apply for an Erasmus grant to help cover the additional expense of living abroad. As a result of these and other initiatives, many programs in universities across the continent now require their students to participate in an international study experience and some have even added international internships and work experience as mandatory curriculum components. Several other international student exchange networks, both formal and informal, also exist in other parts of the world Lopez et al. (2011). The University of Cuenca, for instance, is a member of PAME UDUAL (Programa Académico de Movilidad Educativa de la Unión de Universidades de América Latina y el Caribe). This network also encourages its members to exchange students and focuses in particular on student involvement in Spanish language coursework.

Whereas student exchange programs have been covered from virtually every angle, from incoming to outgoing student perspectives, and from their developmental and educational value to their political, social and cultural implications, relatively little has been done to assess student perceptions about the services that surround them once they arrive at a particular foreign site. Coupled with a relative scarcity of literature on the topic from a Latin-American perspective, and in particular from the Ecuadorian point of view, this study makes a contribution to the existing literature by investigating the perceptions of incoming international students about tourism services in Cuenca, Ecuador, under the assumption that if international student exchange programs are to be successful, they not only need to provide a well-developed and interesting educational experience to incoming students, but also surround them with adequate care and security and give them interesting opportunities to travel and to explore the country during their visits. Additionally, knowing more about international students' experiences and needs is also of great importance to university administrators and faculty. In their efforts to enhance the university's profile, they need to be aware of how international students see the university and its course offerings and how they assess its academic rigor in comparison to their home institutions.

\section{METHODOLOGY AND DATA COLLECTION}

The survey which provided the data for the study was conducted during the months of September and October 2014 among all incoming undergraduate students in the data base of the International Office at the University of Cuenca with valid contact information and e-mail addresses. The data base contained information on 136 international students who had studied at the University since 2011, the year it began to keep records. The students in the database represented various countries, partner universities and programs of study.

\subsection{Questionnaire design}

A questionnaire was designed to gain insight into the students' perceptions of their experiences with tourism services and their living arrangements during their stay at the university. As stated earlier, its primary intent was to determine how the respondents felt about their housing arrangements, travel opportunities, and tourism experiences. Of secondary importance was the fact that this survey provided administrators and educators at the university with valuable information on the provisions they have to make for incoming international students and on how they can enhance their overall experience. Finally, information from the survey would also provide tourism administrators and local politicians with information, not only about the tourism services they provided but also about the needs and perceptions of this particular age group of international visitors and temporary residents in the city of Cuenca.

Since many of the potential respondents had already returned to their home institutions and were no longer in Cuenca, it was decided to collect information using a Web-based survey. The primary reason for doing so was that it could be distributed to a large and widely dispersed audienceat a much lower cost, and much more quickly, than a traditional survey (Schonland \& Williams, 1996; Couper, 2000). Moreover, data collection and data conversion could be done automatically and the target 
audience could be encouraged to participate by means of personal e-mail messages. The most important benefits, however, were the convenience it provided to both the respondents and to the researchers and the likelihood that respondents in this particular age group would respond to a survey in an electronic format, rather than a survey in any of the more traditional formats.

An important concern about Web surveys is their low response rate, especially when sent out to the general population (Tse, 1998; Schaefer \& Dillman, 1998). Yet, in this case, the population under study was relatively small and its members could be reached at their personal e-mail addresses. It was expected that these students would be interested in sharing their opinions about their semester abroad experiences, an expectation that was later supported by the relatively high response rate that was obtained. The questionnaire was a four-page, self-administered instrument. It was estimated that it would take respondents about ten minutes to complete. Most of the questions were closed-ended, requiring a choice from a number of alternatives presented. It also included several open-ended questions that were used to illicit additional, qualitative information. In the first part of the survey respondents were asked to provide demographic information: they were asked to provide information about their gender, age, their country of origin, their home institution, the duration of their stay, their budget for such items as housing, food, entertainment and travel, their living accommodations, their language skills, their means of funding their semester abroad and their exposure to international travel prior to their visit to Cuenca. The second part of the survey collected information about their home institutions and their programs of study and the type of international study program they had participated in.

The third part of the survey looked into the students' motivation to study abroad. Questions used a 1-5 Likert rating scale (1=Not at all important and 5=Extremely Important) to determine why they studied abroad, what the obstacles were to studying abroad, why they had chosen Ecuador, why they had chosen the University of Cuenca, and what they saw as obstacles to living in Cuenca. The fourth part of the survey then looked at their tourism and travel experiences and their perceptions about the service that were offered by the University, the city and the country. It investigated what parts of the country they had visited, how they collected information prior to their travels, what types of tourism they engaged in, how they travelled and where they stayed during their trips. The students were asked to rate their experiences about the various components of the travel experience, from accommodations to means of transportation, and from safety to health issues, when they travelled and for how long. A final numerical question investigated their perceptions about the various tourism experience suppliers, such as tourism offices, tourism operators, restaurants and hotels. The survey concluded with five open-ended questions that asked them to share their recommendations for places to visit for students who come to Cuenca for tourism and for academic purposes, suggestions for the International Office at the University and suggestions for international students considering studying in Cuenca.

Prior to the completion of the survey, a small pilot study was conducted with five international students from various countries who were studying at the University at the time the study was conducted to ensure that the questions and the intent of the survey were clear and to get a sense of how long it would take to answer the questions. Based on the suggestions of the pilot group, several small changes were made to the wording of some of the questions to enhance their clarity.

\subsection{Sample design, data collection and limitations}

As stated earlier, all 136 students who were in the database of the International Office at the University of Cuenca were selected to participate in this study. In the middle of September 2014 an email was sent to all those students with a request to cooperate in the study, with a copy of the survey attached. Two weeks later, in early October 2014, a first reminder was sent out, followed by a second reminder two weeks later. When the survey collection process was closed at the beginning of November 2014, 47 students had responded to the survey, a $34.6 \%$ response rate. Given the concern that was expressed earlier that web surveys generally tend to generate a low response rate, this was deemed good (Tse, 1998; Schaefer \& Dillman, 1998). This paper will first discuss the student demographic data and the descriptive results of the analyses. After that, it will look at the outcomes of various comparative analyses and describe whether any of the observed differences between the groups in the sample were significant. Finally, it will summarize some of the predominant opinions of 
these incoming international students about the benefits and challenges of living, studying and travelling in Ecuador. It will offer its practical implications and theoretical contribution and present limitations and suggestions for future research in its conclusion.

\section{DESCRIPTIVE RESULTS}

\subsection{Demographic information}

A large majority of the respondents (83\%) was female, a pattern that is not uncommon for international studies programs in general (Van Hoof \& Verbeeten, 2005). As Table 1 shows, 20 students (42.6\%) came from South America and 27 students (57.4\%) came from Europe or the United States. Mexico was by far the most common country of origin in South America (36.2\%), as was Germany among the European participants (29.8\%), which can be attributed to the existing partnership programs of the University of Cuenca. Students' ages ranged from 18 to 33 years, with an average of 23 years. Almost all students $(89.4 \%)$ were single (Table 1). Two-thirds (63.8\%) of the students in the sample had travelled abroad before, and Ecuador was the first place for an international exchange program for 33 of them (70.2\%). The students represented a number of academic degree programs, with tourism degrees being the most frequent (46.9\%). This, once again, could be attributed to the nature of the existing international exchange partnerships at the University of Cuenca. A large majority of the students $(85.2 \%)$ indicated that they were part of an international exchange program.

Of interest was the information obtained about students' budgets for various needs and activities, as these drive their ability to pay for services and travel. The overall average budget that students had for their stay at the University of Cuenca was about $\$ 700.00$ per month. As Table 2 shows, the three most important expenditures in the students' budgets were accommodation (\$201.00 on average), food ( $\$ 153.00$ on average) and travel ( $\$ 175.00$ on average). Of interest here was that students' travel budgets were higher than their budgets for food (Table 2). A large majority either shared an apartment $(42.6 \%)$ or lived with a host family $(38.3 \%)$. Their most important sources of income during their semester abroad were scholarships and family support. Student language skills are important not only when it comes to their ability to understand classed taught in Spanish, but also their ability to communicate when travelling in a foreign culture. As was to be expected, students rated their Spanish language ability highest (4.3/5.0) followed by English (3.9/5.0) and German (2.5/5.0). These numbers were reflective and skewed because of the large student contingents from Germany and Mexico in the sample.

\subsection{Student motivations}

The most important motivations for students to study abroad were the multicultural experience it provided them (4.5/5.0), the opportunity to travel (4.4/5.0) and the fact that their home institution had an agreement with the University of Cuenca (3.9/5.0) (Table 3). It was interesting that the reasons why students had decided to study abroad were mostly related to cultural immersion and travel, whereas the obstacles to studying abroad were mostly education related: the most important obstacle was their adaptation to the learning methodology at the University $(2.5 / 5.0)$ followed by Spanish language skills (2.3/5.0) and their teachers adapting to them (2.3/5.0). All of the obstacles to studying abroad received considerably lower ratings than the motivations to studying abroad (Table 3 ).

The most prominent reasons why the respondents had chosen Ecuador for their international study experience were once again cultural: students felt that the opportunity provided them with a variety of multicultural experiences (3.8/5.0) and that Cuenca was a good place to speak Spanish (3.0/5.0). The University of Cuenca was primarily chosen because it had an agreement with the students' home institutions (4.5/5.0). There were very few dominant obstacles to living in Cuenca identified as none of the student opinions received a high average score (Table 3). 
Table 1. Student origins, age and marital status.

\begin{tabular}{|c|c|c|c|c|c|}
\hline \multicolumn{3}{|l|}{ Origin } & \multicolumn{3}{|l|}{ Age } \\
\hline Country & Frequency & Percent & Minimum & Maximum & Mean \\
\hline Mexico & 17 & 36.2 & 18 & 33 & 23.1 \\
\hline Germany & 14 & 29.8 & & & \\
\hline USA & 7 & 14.9 & Marital status & & \\
\hline Belgium & 2 & 4.3 & & Frequency & Percent \\
\hline Brazil & 1 & 2.1 & Single & 42 & 89.4 \\
\hline Colombia & 1 & 2.1 & Married & 4 & 8.5 \\
\hline Czech & 1 & 2.1 & Other & 1 & 2.1 \\
\hline Netherlands & 1 & 2.1 & Total & 47 & 100 \\
\hline Russia & 1 & 2.1 & & & \\
\hline Spain & 1 & 2.1 & & & \\
\hline Venezuela & 1 & 2.1 & & & \\
\hline Total & 47 & 100 & & & \\
\hline
\end{tabular}

Table 2. Student estimated expenses.

\begin{tabular}{cccccccc}
\hline Housing & Food & Handicrafts & Attractions & Entertain & Travel & Other & TOTAL \\
\hline$\$ 201.3$ & $\$ 153.30$ & $\$ 31.30$ & $\$ 73.10$ & $\$ 62.60$ & $\$ 175.0$ & $\$ 58.60$ & $\$ 707.20$ \\
\hline
\end{tabular}

Table 3. Student motivations.

\begin{tabular}{lcccc}
\hline & Minimum & Maximum & Mean & Std. Deviation \\
\hline Motivation & & & & \\
Multicultural experience & 1.0 & 5.0 & 4.522 & .9366 \\
Opportunity to travel & 1.0 & 5.0 & 4.370 & .9969 \\
Institution Agreement & 1.0 & 5.0 & 3.913 & 1.4115 \\
\hline Obstacles & & & & \\
Adaptation to the learning methodology & 1.0 & 5.0 & 2.532 & 1.1951 \\
Spanish language skills & 1.0 & 5.0 & 2.319 & 1.4158 \\
Teachers adapting to students & 1.0 & 5.0 & 2.319 & 1.2355 \\
\hline Reasons for choosing Ecuador & & & & \\
A variety of multicultural experiences & 1.0 & 5.0 & 3.787 & 1.3663 \\
A good place to speak Spanish & 1.0 & 5.0 & 3.043 & 1.7564 \\
Institution agreement & 1.0 & 5.0 & 4.468 & 1.0805 \\
\hline
\end{tabular}

\subsection{Student travel experiences}

With the focus of this study on the student tourism and travel experiences, a large component of the survey was dedicated to questions regarding their travels while in Cuenca. A large majority of the respondents $(89.4 \%)$ had visited different regions of Ecuador during their stay, with the Coast by far the most popular region (Table 4). The respondents who had travelled indicated that recommendations from friends had been their most important source of information, followed by tourist guides. Of interest here was that only two of them (4.3\%) indicated they had relied on the University's International Office for information.

Adventure travel was the preferred type of tourism in Ecuador (38.1\%), followed by leisure tourism (19\%), ecotourism (16.7\%) and rural tourism (14.3\%). Most of the respondents had travelled with international friends (50\%), much more so than with fellow countrymen (19\%); very few of them travelled alone (7.1\%). A large majority $(83.3 \%)$ stated they had organized the trips themselves, that 
the bus was the preferred means of transportation $(76.1 \%)$ and that they generally stayed in hostels (71.4\%) (see Table 4). When asked about their satisfaction levels with their tourism experiences in Ecuador, respondents were most pleased with the kindness of the local people (4.29/5.0). They were generally pleased with the accommodations (3.83/5.0), the organization of tourism activities (3.69/5.0) and information on the Internet (3.64/5.0). They were the least pleased (3.19/5.0) with health related facilities.

Table 4. Student travel experiences.

\begin{tabular}{|c|c|c|}
\hline Travel experience in Ecuador & Frequency & Percent \\
\hline Yes & 42 & 89.4 \\
\hline No & 5 & 10.6 \\
\hline Total & 47 & 100 \\
\hline Region visited & Frequency & Ranking \\
\hline Coast & 22 & 1 \\
\hline Highlands & 9 & 2 \\
\hline Galápagos & 7 & 3 \\
\hline Amazonía & 6 & 4 \\
\hline Tourist info from: & Frequency & Ranking \\
\hline Recommendations of friends & 23 & 1 \\
\hline Tourist guides & 9 & 2 \\
\hline Others & 4 & 3 \\
\hline International office of my home institution & 2 & 4 \\
\hline Videos in YouTube & 2 & 5 \\
\hline Recommendations of my teachers & 1 & 6 \\
\hline Recommendations of my family & 1 & 7 \\
\hline Information related with Ecuador in Internet & 1 & 8 \\
\hline Social network & 1 & 9 \\
\hline Suppliers: tour operators, travel agencies & 1 & 10 \\
\hline Preferred type of tourism in Ecuador & Frequency & Ranking \\
\hline Adventure Tourism & 16 & 1 \\
\hline Leisure & 8 & 2 \\
\hline Ecotourism & 7 & 3 \\
\hline Rural Tourism & 6 & 4 \\
\hline Heritage Tourism & 4 & 5 \\
\hline Others & 4 & 6 \\
\hline Gastronomic Tourism & 1 & 7 \\
\hline Travel companion & Frequency & Ranking \\
\hline International friends & 21 & 1 \\
\hline My own country people & 8 & 2 \\
\hline Local friends & 6 & 3 \\
\hline Others & 6 & 4 \\
\hline Alone & 3 & 5 \\
\hline Journeys organized by: & Frequency & Ranking \\
\hline Myself & 35 & 1 \\
\hline Local tour operators & 4 & 2 \\
\hline Others & 4 & 3 \\
\hline National tour operators & 0 & 4 \\
\hline Preferred transportation & Frequency & Ranking \\
\hline Bus & 32 & 1 \\
\hline Private car & 4 & 2 \\
\hline Others & 4 & 3 \\
\hline Van & 3 & 4 \\
\hline Airplane & 2 & 5 \\
\hline
\end{tabular}


On average, respondents stated they spent about $\$ 26.00 /$ night for accommodations when traveling in Ecuador. The length of the travels was generally no longer than a month, with a small majority (53.2\%) not only travelling in Ecuador but also outside of the country. By far the most popular foreign destinations were Ecuador's neighbors, Peru and Columbia. A large majority (93.6\%) of the respondents stated they would consider returning to Ecuador, and in terms of what aspects of the tourism experience should be improved, the respondents rated transportation as the most in need of improvement, followed by tourism offices, restaurants, and safety/tourist police.

\subsection{Comparative results}

In order to determine if any of the observed differences of opinion among the respondents were significant and in need of additional attention, T-tests were used to compare the various groups. The groups compared in this sample were males and females and incoming students from South America versus incoming students from Europe and the United States. The intent of this comparison was to determine if the University's International Office should take student gender and country of origin into consideration when providing advice to students about their stay and their travel opportunities.

\section{DISCUSSION}

\subsection{The effect of gender on perceptions}

The study first looked at whether the gender of the respondent had any significant effect on his/her motivations to live and study in Cuenca. As there were two groups separated based on the value of a single variable (male-female), and as the level of data provided by the questions using the five-point Likert scale was ordinal, this analysis was done by means of T-tests. In all instances, the null hypotheses assumed that the population means were equal and the alpha level was set at 0.1 .

The data analysis found no significant differences of opinion with regard to why the respondents had chosen to study abroad. However, when asked what they saw as the main obstacles in studying abroad, there were three significant differences of opinion: females saw their fluency in the Spanish language $(\mathrm{p}=0.05)$, the adaptation of local teachers to their style of learning $(\mathrm{p}=0.05)$ and coordination issues with the International Office $(\mathrm{p}=0.00)$ as significantly larger obstacles than their male counterparts (Table 5). Similarly, when asked why they had chosen Ecuador for their international exchange experience, females were significantly more positive about the ease of travelling around the country in a short time $(\mathrm{p}=0.06)$, were more positive about the variety of multicultural experiences

Table 5. The Effect of gender on student perceptions.

\begin{tabular}{|c|c|c|c|c|}
\hline Item & $\mathrm{t}$ & $\mathrm{df}$ & p-value & Mean diff. \\
\hline \multicolumn{5}{|l|}{ Obstacles when studying abroad } \\
\hline Fluency in the Spanish & -2.09 & 15.50 & 0.05 & -0.84 \\
\hline Adaption of teachers to my way of learning & -2.20 & 13.05 & 0.05 & -0.84 \\
\hline Coordination issues in International Relationships Office & -3.44 & 39.58 & 0.00 & -0.80 \\
\hline \multicolumn{5}{|l|}{ Reason to choose Ecuador for international exchange } \\
\hline Easy to travel around the country in a short time & -2.13 & 10.26 & 0.06 & -1.03 \\
\hline Variety of multicultural experiences & -2.47 & 9.00 & 0.04 & -1.40 \\
\hline A good place to speak Spanish & -1.98 & 12.56 & 0.07 & -1.11 \\
\hline \multicolumn{5}{|l|}{ Reason to choose Universidad de Cuenca } \\
\hline A good option to learn Spanish & -2.54 & 10.51 & 0.03 & -1.39 \\
\hline \multicolumn{5}{|l|}{ Obstacles to live in Cuenca } \\
\hline Fluency in Spanish & -3.21 & 15.19 & 0.01 & -1.18 \\
\hline $\begin{array}{l}\text { Lack of knowledge of the people that were close to me } \\
\text { about my local culture }\end{array}$ & -2.73 & 11.33 & 0.02 & -0.96 \\
\hline Lack of updated tourist information available in Internet & -2.37 & 15.98 & 0.03 & -0.62 \\
\hline
\end{tabular}

* For all significant differences between gender, females rated higher than males. 
$(\mathrm{p}=0.04)$ and considered it a good place to study Spanish $(\mathrm{p}=0.07)$. Females also felt significantly more positive about the University of Cuenca as being a good place to study Spanish $(\mathrm{p}=0.03)$ as compared to males (Table 5).

With regard to their perceptions about the obstacles to living in Cuenca, females once again were significantly more concerned about their Spanish language fluency than males $(p=0.01)$, the lack of knowledge of the local people about their own local culture $(\mathrm{p}=0.02)$, and about the lack of updated tourist information that was available on the Internet $(\mathrm{p}=0.03)$ (Table 5).

\subsection{The effect of country of origin on perceptions}

The second comparison this study performed was to look at whether there were any significant differences in the experiences and opinions between incoming students from South America and incoming students from Europe and the United States. Once again, T-tests were used to determine if any of the differences of opinions were significant. As was to be expected, there were some significant differences between the two groups of students with regard to their language controls. South American students were significantly more confident about their Spanish language skills, whereas the European/US students were significantly more confident about their English and Germans language abilities. German language skills were a direct result of the fact that many of the incoming students were from partner institutions in Germany (Table 6). When asked if they had

Table 6. The effect of country of origin on perceptions.

\begin{tabular}{|c|c|c|c|c|c|c|}
\hline 1 - South America / 2 - Europe/US & Origin & Mean & $\mathrm{t}$ & $\mathrm{df}$ & p-value & Mean diff. \\
\hline \multicolumn{7}{|l|}{ Control of language } \\
\hline \multirow[t]{2}{*}{ Spanish } & 1 & 4.95 & 7.36 & 31 & 0.00 & 1.21 \\
\hline & 2. & 3.74 & & & & \\
\hline \multirow[t]{2}{*}{ English } & 1 & 3.25 & -5.74 & 33 & 0.00 & -1.19 \\
\hline & 2 & 4.44 & & & & \\
\hline \multirow{2}{*}{ German } & 1 & 1.06 & -6.11 & 25 & 0.00 & -2.34 \\
\hline & 2 & 3.40 & & & & \\
\hline \multicolumn{7}{|l|}{ Previous abroad travel } \\
\hline & 1 & 1.80 & 7.71 & 25 & 0.00 & 0.76 \\
\hline & 2 & 1.04 & & & & \\
\hline \multicolumn{7}{|l|}{ Ecuador is the first place for } \\
\hline \multirow[t]{2}{*}{ international exchange } & 1 & 1.10 & -2.89 & 44 & 0.01 & -0.34 \\
\hline & 2 & 1.44 & & & & \\
\hline \multicolumn{7}{|l|}{ Reason to study abroad } \\
\hline \multirow[t]{2}{*}{ Recommended by friend } & 1 & 2.74 & 2.10 & 36 & 0.04 & 0.90 \\
\hline & 2. & 1.84 & & & & \\
\hline \multirow[t]{2}{*}{ Home university agreement } & 1 & 4.47 & 2.57 & 43 & 0.01 & 0.96 \\
\hline & 2 & 3.52 & & & & \\
\hline \multirow[t]{2}{*}{ Learn Spanish } & 1 & 1.47 & -9.81 & 30 & 0.00 & -3.06 \\
\hline & 2 & 4.54 & & & & \\
\hline \multicolumn{7}{|l|}{ Obstacles when studying abroad } \\
\hline \multirow[t]{2}{*}{ Fluency in Spanish } & 1 & 1.40 & -5.00 & 41 & 0.00 & -1.60 \\
\hline & 2 & 3.00 & & & & \\
\hline \multirow[t]{2}{*}{ Issues of coordination } & 1 & 1.40 & -2.20 & 43 & 0.03 & -0.67 \\
\hline & 2 & 2.07 & & & & \\
\hline \multicolumn{7}{|l|}{ Reason to choose Ecuador } \\
\hline \multirow[t]{2}{*}{ The only available option } & 1 & 2.40 & 3.11 & 24 & 0.01 & 1.18 \\
\hline & 2 & 1.22 & & & & \\
\hline \multirow[t]{2}{*}{ A good place to speak Spanish } & 1 & 1.30 & -11.78 & 44 & 0.00 & -3.03 \\
\hline & 2 & 4.33 & & & & \\
\hline \multicolumn{7}{|l|}{ Reason to choose Cuenca } \\
\hline \multirow[t]{2}{*}{ The only available option } & 1 & 2.68 & 1.80 & 37 & 0.08 & 0.80 \\
\hline & 2 & 1.89 & & & & \\
\hline \multirow[t]{2}{*}{ A good option to learn Spanish } & 1 & 1.37 & -8.19 & 44 & 0.00 & -2.59 \\
\hline & 2 & 3.96 & & & & \\
\hline
\end{tabular}


travelled abroad before, the US/European students proved significantly more experienced than their peers from South-America $(\mathrm{p}=0.00)$. Similarly, whereas for many of the South American students Ecuador was the first place they had visited on exchange, this was significantly less common for European/US students $(\mathrm{p}=0.01)$ (Table 6).

With regard to the reasons why students from the various continents had decided to study abroad, there were several significant differences as well: South American students relied more on the recommendations of friends than students from Europe and the US $(p=0.04)$ and they had come to Cuenca because it was part of an agreement their home institution had with the University of Cuenca $(\mathrm{p}=0.01)$, significantly more so than for the US/European students. As was to be expected, one of the most important motivations for the US/European respondents was to learn Spanish $(\mathrm{p}=0.00)$ (Table 6).There were some significant differences with regard to the obstacles to studying abroad that were identified by the respondents: Spanish language fluency was a significantly bigger obstacle for the European/US students $(\mathrm{p}=0.00)$, as were issues with program coordination $(\mathrm{p}=0.03)$ (Table 6).

South-American respondents indicated significantly more often that both the country of Ecuador and the University of Cuenca were the only options available for them to study abroad. Alternatively, the US/European respondents considered it a good place to speak and learn Spanish, as was to be expected $(\mathrm{p}=0.00)($ Table 6$)$.

\subsection{Qualitative feedback}

Besides providing numerical feedback, the survey also asked the respondents to share their opinions and suggestions about their experiences by means of five open-ended questions at the end of the survey. The following paragraphs will summarize their opinions, which were expressed in both Spanish and English.

\subsection{Recommendations for future international students of places to visit in Ecuador}

When asked which places they would recommend future international students to visit, responses were extensive and included virtually every major tourism site in Ecuador, from the Galápagos and the Orient to the Coast and the major cities in the country. Several respondents highlighted Cuenca's tourism sites as well, and others raised a word of caution by saying that future students should avoid the most heavily visited tourist sites. The beach was mentioned numerous times as a good site to visit for young people.

\subsection{Recommendations for improvements at the International Office at the University of Cuenca}

Much more important were the recommendations the respondents provided for the International Office at the University of Cuenca. Respondent suggestions ranged from more support in academic scheduling to more attention to the students' basic needs with regard to living, health and travel. Some suggested the creation of a Website with information on available apartments in town and asked for more clarity with regard to arrival and departure information. Several respondents asked for the International Office to organize more integration activities for the international students, both with each other and with local students, and for better organization of the student trips. In general, the students asked for more clarity about academic requirements and the university in general, more information about accommodation in town, more group outings and more integration activities. US/European students in particular complained about the fact that they had to pay an additional fee for Spanish language classes.

\subsection{Recommendations to international students visiting Cuenca}

Many of the suggestions provided were related to the enjoyment of the opportunity and to make an effort to understand the local culture in Cuenca and Ecuador. Respondents stated that future visitors should attempt to get to know the local population and travel as much as possible. Several suggested that it would be important for future visitors to learn Spanish prior to their stay in Cuenca, to practice it as much as possible while interacting with locals rather than international students, and to learn 
about the city and the university prior to arrival. Several US/European students mentioned that the academic level at the University of Cuenca was not as high as at their home institutions, which, in turn, meant that they had primarily focused on learning Spanish. In general suggestions were positive: US/European respondents saw the experience as a great opportunity to learn Spanish and to become familiar with the local culture and its welcoming people.

\section{CONCLUSION}

Students participating in international exchange programs have been shown to benefit from the experience in numerous ways: they gain appreciating for other cultures and ways of life, they gain academic experience, they have opportunities to travel, they grow and mature in the process and they are generally better prepared for the challenges that life will present them after they complete their studies. If they can survive and flourish in a different culture and in a different foreign environment, they will certainly be able to survive and flourish in their home countries as they start their professional careers.

The study presented here looked at one particular aspect of the international student exchange process: the perceptions and experiences of incoming international student at the University of Cuenca, Ecuador. Its objective was to determine the students' needs and opinions, with a special focus on their travel behaviors, and to provide the university and its International Office with information that can be used to further improve the academic and personal experiences of future generations of incoming international students, thereby making the university a better and more desirable exchange partner for international universities. As the University of Cuenca hopes to raise its academic and research profile, improving its stature as a solid, well-organized foreign exchange partner helps in accomplishing that goal.

A sample of 47 incoming international students who had studied at the University of Cuenca between 2011 and 2013 and whose contact information had been captured in the data base of the International Office was surveyed. Large contingents in the sample originated from either Mexico or Germany, which was a direct result of the more active exchange agreements that exist in the University of Cuenca. This pattern is common in many international universities, where students only have the opportunity to study abroad at certain predetermined foreign partner institutions. The students were primarily motivated to study abroad by a desire to have a multicultural experience and to have the opportunity to travel. They saw academic issues, such as different learning methodologies and teaching techniques, as well as the Spanish language as the major obstacles. The most important reason why they had studied in Cuenca was the aforementioned existence of an exchange agreement between their home institution and the University of Cuenca. The respondents indicated they had travelled extensively in Ecuador and that they had primarily relied on information from friends. Very few of them had used the International Office for travel information. As was to be expected for this age group, adventure and leisure/beach travel were the favorite forms of travel. They mostly travelled with friends, organized their own trips and used the bus as their preferred means of transportation. They commented on the kindness of the locals and most of them stated they would come back to Ecuador in the future.

The study found some significant differences of opinion between males and females. In general, females were found to be more positive about their academic and travel experiences than males, yet also expressed higher concerns about some of the obstacles. The study then looked at whether student origins would generate any significant differences of opinion and found some interesting information: US/European students had significantly more foreign travel experience than their peers from South America: South American students relied more on the advice of their friends and family than students from the US/Europe in making their study abroad decisions, a trend that is more common in collectivistic cultures such as Mexico than in individualistic cultures such as Germany or the US. US/European students were primarily in Cuenca to learn Spanish and also saw the language as a greater obstacle than their peers from South America. 
In making recommendations, the respondents were mostly generous in their comments: they mentioned the International Office should pay more attention to introducing them to the university environment and their new academic settings. They also mentioned that they felt they could have benefited from more information about basic needs, in particular housing, prior to their arrival in Cuenca. They indicated that more integration activities would be helpful; US/European students they did not like the fact they had to pay extra for Spanish language classes.

\subsection{Implications}

Given the scarce literature on the topic in the South American academic setting, this study contributes to the literature in that it provides some insight into how foreign students perceive their studies and experiences at a regional university in Ecuador. It has practical implications for the University and its International Office in the suggestions for improvement that were made by the respondents and the insight it provided into the students' academic needs: their budgets, their travel behaviors and their academic experiences. The needs of South American and US/European students were clearly different and the International Office should be aware of those differences: whereas US/European students are experienced travelers, for many South American students this was the first international experience, reason why they might deserve extra attention. On the other hand, US/European students need additional support with the language and in their adjustments to the academic climate. Specific comments about how information was provided prior to student arrival, student housing, and Spanish language education stood out in that regard.

\subsection{Limitations and future research}

This study only looked at students in the database of one university in Ecuador and used a small sample. Even though its results can and most likely will apply to other universities in the country and on the continent, they cannot be generalized beyond the scope of the research presented here. Students in the sample came primarily from two partner institutions of the University of Cuenca, reason why opinions might have been skewed by the responses from Mexican and German students in the sample. The sample was relatively small and future studies need to ensure that the number of respondents is more representative of the overall population studied. Finally, this study was exploratory in nature and was intended to gain initial information about perceptions and travel behaviors of incoming international students at the University of Cuenca. It did not assign any causal relationships as those were beyond the scope of the study.

Further research could explore the topic at other universities in Ecuador and in other countries and engage in greater comparative analyses between universities and countries. Several questions can be raised that could generate interesting new research topics: Are these experiences and perceptions characteristic of students at the University of Cuenca or are they similar to the experiences and perceptions of students at other universities? Are there differences between countries in how they welcome and treat students? What are the differences in travel experiences between South American and US/European students and what causes those differences? And, most importantly, how can this information be used to enhance the international student experience and place the University of Cuenca in the best possible light as its grows its international presence and improves its academic stature in Ecuador and abroad?

\section{REFERENCES}

Altbach, P., J. Knight, 2007.The globalization of international education. J. Stud. Int. Educ., 11(3-4), 290-305.

Altbach, P., U. Teichler, 2001. Internationalization and exchanges in a globalized university. J. Stud. Int. Educ., 5(1), 5-25. 
Arndt, R.T., 1984. Rethinking international education. In: Olson, W.C., L.D. Howell (Eds.). International Education: The Unfinished Agenda (pp. 1-39). Indianapolis, IN: White River Press, Inc.

Barnett, G.A., R.Y. Wu, 1995. The international student exchange network: 1970 \& 1989. High. Educ., 30, 353-368.

Brunner, J., 2009. The Bologna Process from a Latin American Perspective. J. Stud. Int. Educ., 1-22.

Calleja, J., 1995. International education: A common direction for our future. In: Calleja, J. (Ed.). International Education and the University (pp. 41-57). Bristol, PA and London: Jessica Kingsley Publishers.

Carlson, J., K. Widaman, 1988. The effects of study abroad during college on attitudes toward other cultures. IJIR, 12(1), 1-17.

Carrera, P., 2010. Diseño del sistema académico por competencias de la Escuela de Turismo y Hospitalidad de la Pontificia Universidad Católica del Ecuador. Gestión Turística (Valdivia), 13, 93-112.

Chieffo, L., L. Griffiths, 2004. Large-scale assessment of student attitudes after a short-term study abroad program. Frontiers: The Interdisciplinary Journal of Study Abroad, 10(10), 165-177.

Couper, M.P., 2000.Web Surveys: A review of issues and approaches. POQ, 64(4), 464-494.

Daly, A., M. Barker, 2010. Australian universities' strategic goals of student exchange and participation rates in outbound exchange programmes. J. High. Educ. Pol. Manag., 32(4), 333-342.

Doyle, S., P. Gendall, J. Hoek, C. Tait, L. McKenzie, 2010. Investigation of factors associated with student participation in study abroad. J. Stud. Int. Educ., 14(5), 471-490.

Drews, D., Meyer, L., Peregrine, P., 1996. Effects of study abroad on conceptualizations of national groups. Coll. Stud. J., 30, 452-461.

Fernández, C., P. Zaldívar, F. Enríquez, 2013. Turismo alternativo y educación: Una propuesta para contribuir al desarrollo humano. El Periplo Sustentable: Revista de Turismo, Desarrollo y Competitividad, 24, 125-154.

Frisch, N.C., 1990. An international nursing student exchange program: An educational experience that enhanced student cognitive development. J. Nurs. Educ., 29(1), 10-12.

Gacel Avila, J., 2007. The process of internationalization of Latin American higher education. J. Stud. Int. Educ., 11(3-4), 400-409.

Hadis, B., 2005. Why are they better students when they come back? Determinants of Academic Focusing Gains in the Study Abroad Experience. Frontiers: The Interdisciplinary Journal of Study Abroad, 11, 57-70.

Juvan, E., M. Lesjak, 2011. Erasmus Exchange Program: Opportunity for professional growth or sponsored vacations? J. Hosp. Tour. Educ., 23(2), 23-29.

Lamey, S.L., 1990. Global education: A conflict of images. In: Tye, K.A. (Ed.). Global Education: From Thought to Action (pp. 49-66). Alexandria, VA: Association for Supervision and Curriculum Development.

Lawson, D., D.S. White, S. Dimitriadis, 1998. International business education and technology-based active learning: Student-reported benefit evaluations. J. Market. Educ., 20(2), 141-148.

Lopez, D., D. Lopez, L. Andrade, B. Lopez, 2011. Functional patterns in international organizations for University Cooperation in Latin America and the Caribbean. J. Stud. Int. Educ., 15(2), 203-215.

Messer, D., S. Wolter, 2001. Are student exchange programs worth it? QHE, 7(3), 647-663.

Mohareji, E., J. Gillespie, 2003. How study abroad shapes global careers: Evidence from the United States. J. Stud. Int. Educ., 25(1), 43-70.

Mutlu, S., 2011. Development of European consciousness in Erasmus students. J. Cult. Soc., 2/2011, $87-102$. 
Paige, R., G. Fry, E. Stallman, J. Josic, J. Jon, 2009. Study abroad for global engagement: the longterm impact of mobility experiences. Intercultur. Educ., 20(1), S29-S44.

Palese, A., A. Zabalegui, A. Sigurdadottir, M. Bergin, B. Dobrowolska, C. Gasser, M. Pajnkihar, C. Jackson, 2014. Bologna Process, More or Less: Nursing education in the European Economic Area: A Discussion Paper. Int. J. Nurs. Educ. Scholarsh., 11(1), 63-73.

Pechar, H., 2007. The Bologna Process: A European Response to Global Competition in Higher Education. CJHE, 37(3), 109-125.

Remy, R.C., J.A. Nathan, J.M. Becker, J.V. Torney, 1975. International learning and international education in a global age. Washington, D.C.: National Council for the Social Studies.

Roberts, E.H., 1998. The innocents abroad. Do students face international internships unprepared? CHRAQ, 39(4), 64-69.

Rodriguez-Gonzalez, C., R. Bustillo Mesanza, P. Mariel, 2011. The determinants of international student mobility flows: an empirical study on the Erasmus program. High. Educ., 62(4), 413-430.

Saliba, M. (1995).An institutional framework for international education.In J. Calleja (Ed.), International Education and the University (pp. 58-80). Bristol, PA and London: Jessica Kingsley Publishers.

Schaefer, D.R., D.A. Dillman, 1998. Development of standard e-mail methodology: Results of an experiment. $P O Q, 62(3), 378-397$.

Schonland, A.M., P.W. Williams, 1996.Using the Internet for travel and tourism survey research: Experiences from the Net traveler survey. J. Travel Res., 35(2), 81-87.

Silberleib, N., 2005. El turismoeducativo y surelación con las políticas culturales de Buenos Aires. Turismo Cultural, 81.

Souto-Otero, M., J. Huisman, M. Beerkens, H. De Wit, S. Vujic, 2013. Barriers to international student mobility: Evidence from the Erasmus program. Educ. Res., 42(2), 70-77.

Stangor, C., K. Jonas, W. Stroebe, M. Hewstone, 1994. Influence of student exchange on national stereotypes, attitudes, and perceived group variability. Eur. J. Soc. Psychol., 26, 663-675.

Stone, M., J. Petrick, 2014. The educational benefits of travel experiences: A literature review. $J$. Travel Res., 52(6), 731-744.

Sutton, R., D. Rubin, 2004. The glossary project: Initial findings from a system-wide search initiative on study abroad learning outcomes. Frontiers, 10(4), 65-82.

Swanson, G.I., 1969. International education: Portents for the future. In: Paulsen, F.R. (Ed.), Changing dimensions in International education (pp. 1-8). Tucson, AZ.: The University of Arizona Press.

Tse, A.C., 1998. Comparing the response rate, speed and response quality of two methods of sending questionnaires: E-mail vs. mail. JMRS, 40(4), 353-361.

Vestal, T.M., 1994. International education: Its history and promise for today. London: Praeger Publishers.

Van der Wende, M., D. Westerheijden, 2010. International aspects of quality assurance with a special focus on European higher education. QHE., 7(3), 223-245.

Van Hoof, H., 2006. Searching for the holy grail of international education: Feedback from hospitality management study abroad participants. FIU Hospitality Rev., 24(1), 49-59.

Van Hoof, H., M.J. Verbeeten, 2005. Wine is for drinking, water is for washing. Student perceptions about international exchange programs. J. Stud. Int. Educ., 9(1), 42-61. 